\section{Letter from Field}

\section{Check for updates}

\section{OPEN ACCESS}

Received: Nov 7, 2019

Accepted: Nov 10, 2019

Correspondence to

Sung-In Kim

Seoul National University College of Medicine, 103 Daehak-ro, Jongno-gu, Seoul 03080,

Korea.

E-mail: sunginkim@snu.ac.kr

(c) 2019 Korean Society of Global Health. This is an Open Access article distributed under the terms of the Creative Commons Attribution Non-Commercial License (https:// creativecommons.org/licenses/by-nc/4.0/) which permits unrestricted non-commercial use, distribution, and reproduction in any medium, provided the original work is properly cited.

ORCID IDs

Juyoung Kang (iD)

https://orcid.org/0000-0003-1184-5546

Sangil Yun (D)

https://orcid.org/0000-0002-3931-5128

Sung-In Kim (D)

https://orcid.org/0000-0001-7627-2756

Conflict of Interest

No potential conflict of interest relevant to this article was reported.

Author Contributions

Writing - original draft: Kim SI, Kang J, Yun S.

\section{A journey toward building friendship with the marginalized in global health}

\author{
Juyoung Kang (D), Sangil Yun (D), Sung-In Kim (iD \\ Seoul National University College of Medicine, Seoul, Korea
}

\section{HOW CAN WE HELP THE MARGINALIZED IN DEVELOPING COUNTRIES?}

This fundamental question crossed our minds on a late night at a bench after the 'basic anatomy' class in the first semester of medical school. At that time, we were not very clear on how we could help others and who we could help. However, we strongly believed that meeting the people in need would be the starting point of our journey to answer this question. The more we became aware of the field of global health, the clearer our question became. Under the teaching of Prof. Juhwan Oh (JW Lee Global Medicine Center, Seoul, Korea), we planned and visited developing countries every year. During the preparation of our trips, we tried to understand not only about the health problems of the countries we visited, but also about the critical issues of global health itself by reading books and watching movies such as 'Reimagining Global Health' and 'Bending the Arc.' We also studied qualitative research methodologies to learn how to better listen to other people.

Through our 4 outreach trips to Malawi, Nepal, Cuba and Ghana, we realized that global health is not about hastily providing health solutions to other countries. Rather, the 'real' meaning of global health is about building friendship- the process of respecting and treating others in an equal position, understanding challenges through sincere communication and solving problems together with the sense of co-working. In this article, as a reflection 4th year medical students heading to graduation, we would like to share our journey in navigating the meaning of 'friendship.'

\section{HEARING THE VOICE OF LOCAL PEOPLE IN MALAWI}

First, we visited Daeyang Luke's Hospital in Malawi in East Africa and participated in a project of a startup company called NOUL (Yongin, Korea). The aim of the project was to develop a machine using artificial intelligence (AI) to diagnose malaria (Fig. 1). For the project, we collected blood smear samples of malaria patients in the hospital laboratory for about 5 days. The samples were collected to be used for AI training. We also had opportunities to meet with American nurses, doctors, and students who came to serve the hospital, visit national hospitals and government agencies of Malawi and stroll through the villages near the hospital. 


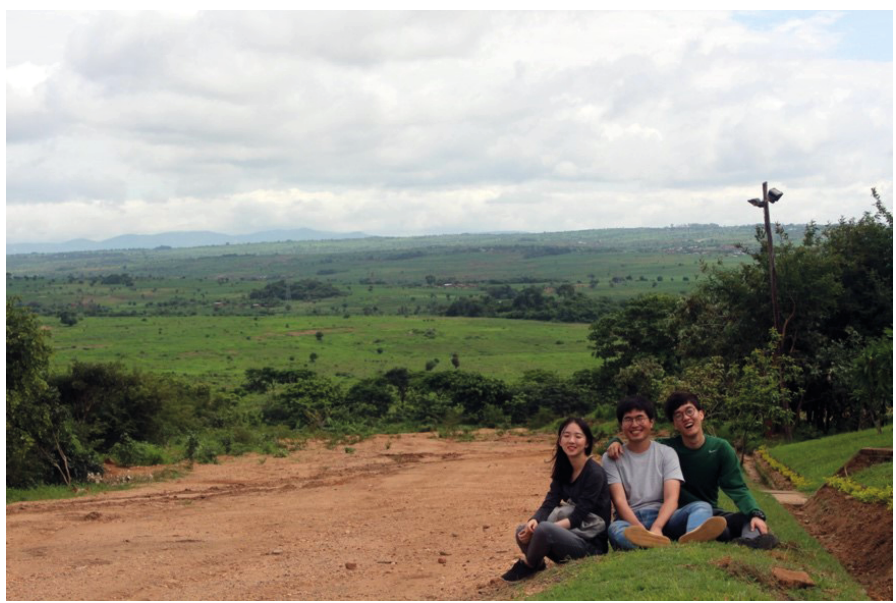

Fig. 1. First outreach trip to Daeyang Luke Hospital in Lilongwe, Malawi.

While we were staying in Malawi, we realized that we did not put much value in listening to the opinions of the local people. We only focused on the importance and solutions of malaria problem in Malawi during our preparation. Ironically, when we asked the people about the most important problem in Malawi, people always answered 'hunger.' They could not be cured not because there were no proper cures for the disease but simply because they did not have enough money to pay for hospitals or eat enough food. What really surprised us was that the local people had their own ideas to deal with malaria. Nursing students and technical staff who helped the project in Malawi had better understanding of the problem of malaria than we had, with our knowledge from textbooks. Also, they shared their knowledge and idea about how they are trying to solve the problem. We realized how ignorant it was to try to define and solve the problems of developing countries in our own ways. At the same time, new question came to our mind- how can we hear the voice of local people better?

\section{EXPERIENCING THE WARMTH OF FRIENDSHIP IN NEPAL}

To answer to our new question, we decided to visit Dhulikhel Hospital in Nepal founded by the local doctors themselves. We wanted to learn about Nepalese efforts in solving their health problems by observing the community health program of the hospital, which provides healthcare services to the remote villages that have access difficulty to hospitals. For 2 weeks, we visited Bolde and Kirnetar outreach centers with Nepalese staff and participated in community programs such as school hygiene programs and contraception education for women (Fig. 2).

After receiving warm hospitality from the staffs, we realized that building relationships with the locals should be the first step in dealing with health problems. We spent many days together to understand each other. We climbed mountains, ate food together, and talked about each other's cultures, religions, and lives. By far the most memorable time is the time when we sang songs of each country—-Resham Firiri and Gangnam Style-together in front of a bonfire. Through those times, we could naturally talk in depth about Nepal's health problems and listen to their efforts with sincere desire to help others.

Another thing we learned was that the community-based health system in Dhulikhel Hospital made their good intentions more sustainable and effective. On the other hand, the community- 


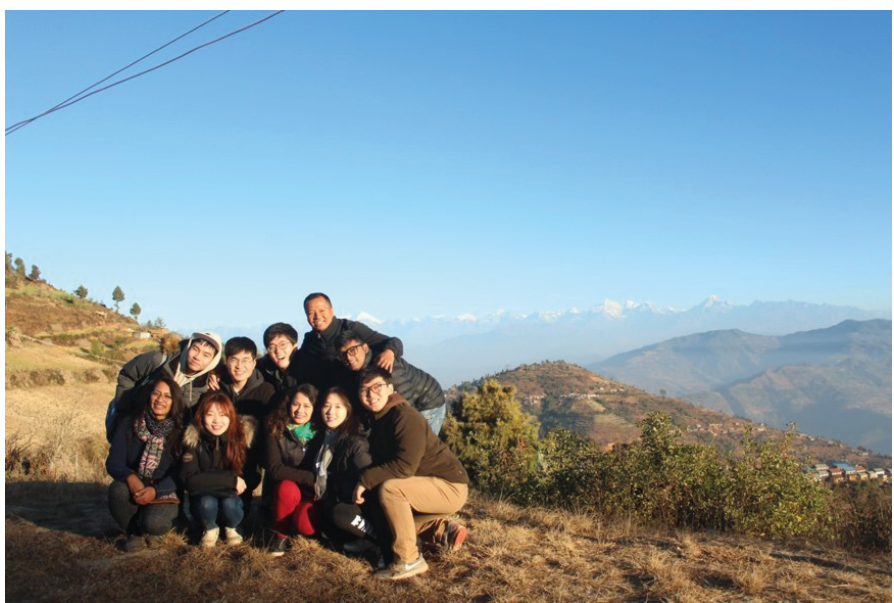

Fig. 2. At one of the mountains in Bolde with Nepalese staffs of Dhulikhel Hospital.

based system of the hospital had several difficulties in terms of financial support and expansion of the system from hospital-based to national level. We then wondered about how other countries promote community-based health system and how international aid agencies support them. To find out the answer, we continued our journey by dividing into 2 groups.

\section{RECOGNIZING THE STRENGTH OF PRIMARY HEALTH CARE SYSTEM IN CUBA}

One of our groups headed to Cuba. Even though Cuba's Gross Domestic Product (GDP) is much lower than that of South Korea and United States, Cuba's under-5 mortality was similarly low as the 2 countries because of its primary health care system. Under the guidance of professors at Escuela Nacional de Salud Pública (ENSAP), we experienced the health care system, family medicine and medical education of Cuba under socialist culture during our 30 days-trip.

We realized that the role of family doctors is crucial in maintaining the well-organized health system. By participating in the works of outpatient clinics in Policlínico (multispecialty and multiservice clinic) and home visits of family doctors in Consultorio (office of family doctors and nurses), we realized that the doctors were concerned with the social and economic situations as well as the health of people they were in charge of. In addition, family doctors mediated the use of medical resources effectively through an active referral system. They not only referred and counter-referred patients to hospitals vertically, but also connected patients to various primary care institutions horizontally (Fig. 3).

We also learned that medical education is essential in maintaining the national health system. From first year, Cuban medical students were already exposed to the clinical setting and real situations where medical practitioners and social workers collaborated. They followed family doctors from the beginning of their medical studies and learned about the strength of community-oriented primary health care since then. Our visit to Cuba humbled us because Cuba was promoting community-based health system so well and there were many lessons we could learn from them. 


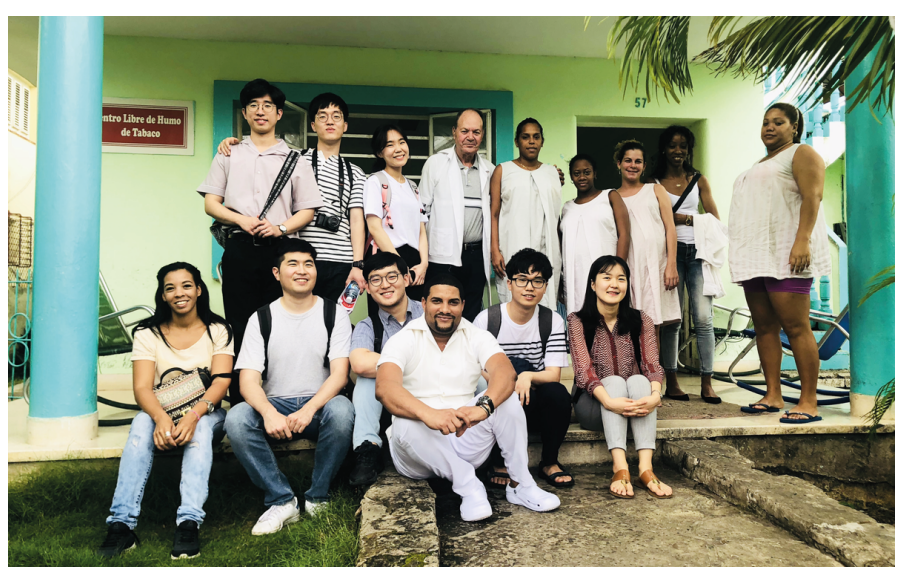

Fig. 3. At hogar materno 'Isamaelillo' (maternal home for pregnant women in high risk) with professors of Escuela Nacional de Salud Pública and Cuban pregnant women.

\section{OBSERVING THE POTENTIAL OF COOPERATIVE DEVELOPMENT IN GHANA}

The other group headed to Ghana as we heard about some good results there in implementing a project focused on meeting their own needs rather than relying on unilateral aid from others. Korea International Cooperation Agency (KOICA) and Korea Foundation for International Healthcare (KOFIH) were implementing projects based on Ghana's pre-existing health care system and resources. To experience these program-based approach projects, we stayed in Ghana for 24 days (Fig. 4).

We learned about the real aspects of cooperation with local staffs by meeting our alumnus-a surgeon who has been training laparoscopic skills since 2016 on the request of Ghanaian doctors. On the other hand, through the experience of KOICA projects which aim to strengthen the pre-existing community-based health service delivery system, we were able to see the prospect of sustainable form of aid. For instance, in Krachi West District, the maternal health index has risen from the bottom to the top rank after implementing KOFIH funded projects proposed by the local staffs based on the local needs. The authorities expressed satisfaction to this form of aid and the partnership provided.

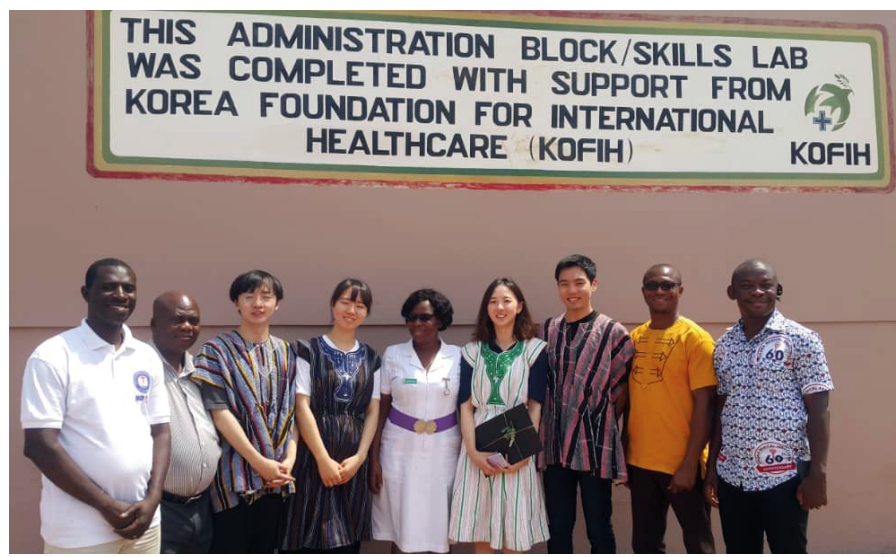

Fig. 4. In front of Korea Foundation for International Healthcare supported building with Dr. Abiwu and local staffs in from Krachi west region, Ghana. 
As in Malawi, we were able to understand the importance of communication between staffs from different cultural backgrounds after co-working in various projects. Overall, it was a precious experience as we could see the potential of pioneering approaches to global health projects which focus on listening to the needs of recipient countries.

\section{TOWARD BUILDING FRIENDSHIP WITH THE MARGINALIZED}

"Teach a hungry man how to fish rather than giving him a fish." This is a famous quotation in global health that describe the type of aid that should be provided. Our journey from Malawi to Ghana was not only about finding the answer on 'how to resolve hunger.' We have also tried to understand who the people we met really are, and how they became hungry. Throughout the journey, our focus has changed from studying the prevalent 'disease' to building relationships with the 'people,' and from saying what we think the problem is to listening to what the people really think.

We still do not have a clear answer to our first question "how can we help the marginalized in developing countries?" However, what became clear is that the journey for past 4 years will be the milestone for guiding our future direction. We will keep going to the places where people in need exist and hear their voices on what they really need. We hope our journey toward sharing 'friendship' with the marginalized will be a small step toward "Health for All." 